\title{
Rituximab Monotherapy for Primary Cutaneous Follicle Center Lymphoma
}

\author{
Ajay Dhakal, ${ }^{a}$ David M Tretheway, ${ }^{b}$ Rebecca Fulton, ${ }^{b}$ Binay Kumar Shah*c \\ ${ }^{a}$ Clinical Observer, ${ }^{b}$ Pathologist, ${ }^{c}$ Hematologist and Medical Oncologist \\ St. Joseph Regional Medical Center, Lewiston ID, USA
}

\author{
Date of submission \\ November 27th, 2011 \\ Date of acceptance \\ December 14th, 2011 \\ Available online \\ January 25th, 2012

\section{Keywords} \\ PCFCL, rituximab, radiotherapy

\section{Citation} \\ Dhakal A, Tretheway DM, Fulton $R$, et al. \\ Rituximab monotherapy for primary cutaneous \\ follicle center lymphoma. Journal of Advances \\ in Internal Medicine. 2012;01(1)16-18.
}

\begin{abstract}
Primary cutaneous follicle center lymphoma is a rare disorder. Although there are several treatment options, large clinical trials on the treatment of primary cutaneous follicle center lymphoma are lacking. Optimal treatment of this disease is unclear. We describe a case of primary cutaneous follicle center lymphoma treated with systemic rituximab, and review the literature.
\end{abstract}

\section{INTRODUCTION}

Primary cutaneous lymphoma is an uncommon disease with estimated incidence of $1 / 100,000 .{ }^{1}$ Primary cutaneous follicle center lymphoma (PCFCL) is the most common subtype of primary cutaneous lymphoma. ${ }^{2}$ PCFCL occurs primarily in the elderly with a median age of 51 years and male to female incidence ratio of $1.84 .^{3,4}$ Due to the rarity of the disease, large clinical trials on the treatment of PCFCL are lacking. Optimal treatment of the disease is less clear and based on case reports and small case series. In this article, we present a case of PCFCL treated with systemic rituximab, and review the literature.

\section{CASE REPORT}

Presentation: A 53-year-old Caucacian man presented to the oncology clinic with a six-month history of a slowly enlarging, painless mass on the neck. The patient denied any weight loss, fever or night sweats. Review of systems was negative. Physical examination was significant for a $3 \times 3 \mathrm{~cm}$ non-tender mass on the left cervical region. Systemic examination was normal. There was no hepatomegaly, splenomegaly or lymphadenopathy. CT scan of the neck showed a $3 \times 3 \mathrm{~cm}$ well circumscribed mass in the soft tissues underneath the subcutaneous regions. An excisional biopsy of the mass showed a dermal lymphoid infiltrate forming large, irregular follicles (Figure 1).

The follicles were composed of CD20+, CD79a+ B cells with strong BCL6 positivity (Figure 2, Figure 3, Figure 4) and weak CD10 expression. The neoplastic cells were negative for BCL2, CD5 and cyclinD1. These findings were consistent with a diagnosis of primary cutaneous follicle center lymphoma. The patient's complete blood count and metabolic panel were within normal limits. He was negative for HIV-1, HIV-2, hepatitis B surface antigen, hepatitis B surface antibody and hepatitis B core antigen. Serum Beta-2 microglobulin was $0.87 \mathrm{~g} / \mathrm{ml}$. CT scan of chest, abdomen and pelvis did not show any lymphadenopathy or suspicious lesions. Bone marrow examination was negative for involvement with lymphoma. Based on these findings, the patient was diagnosed with localized primary cutaneous follicle center lymphoma.

Treatment: After discussion with the patient about several treatment options, the decision was made to treat him with intravenous rituximab $375 \mathrm{mg} / \mathrm{m}^{2}$ once a week for four weeks.

Outcome and follow up - The painless mass on the neck completely resolved after completion of the treatment. Patient is currently being followed up every three monthly with history, physical examination. Patient is currently in complete remission for last six months.

\section{DISCUSSION}

PCFCL is defined as a tumor of neoplastic follicle centers with predominance of large centrocytes and variable number of centroblasts which may have a follicular, follicular and diffuse, or diffuse type of growth pattern. ${ }^{5} 68.9 \%$ cases occur in the head and neck region. ${ }^{4}$ The clinical course is generally favorable with a five year survival rate exceeding $95 \%$. 4,8

\footnotetext{
* Corresponding author

Hematologist and Medical Oncologist

St. Joseph Regional Medical Center, 1250 Idaho Street, Lewiston ID USA 99403

Email address - binay.shah@gmail.com
} 


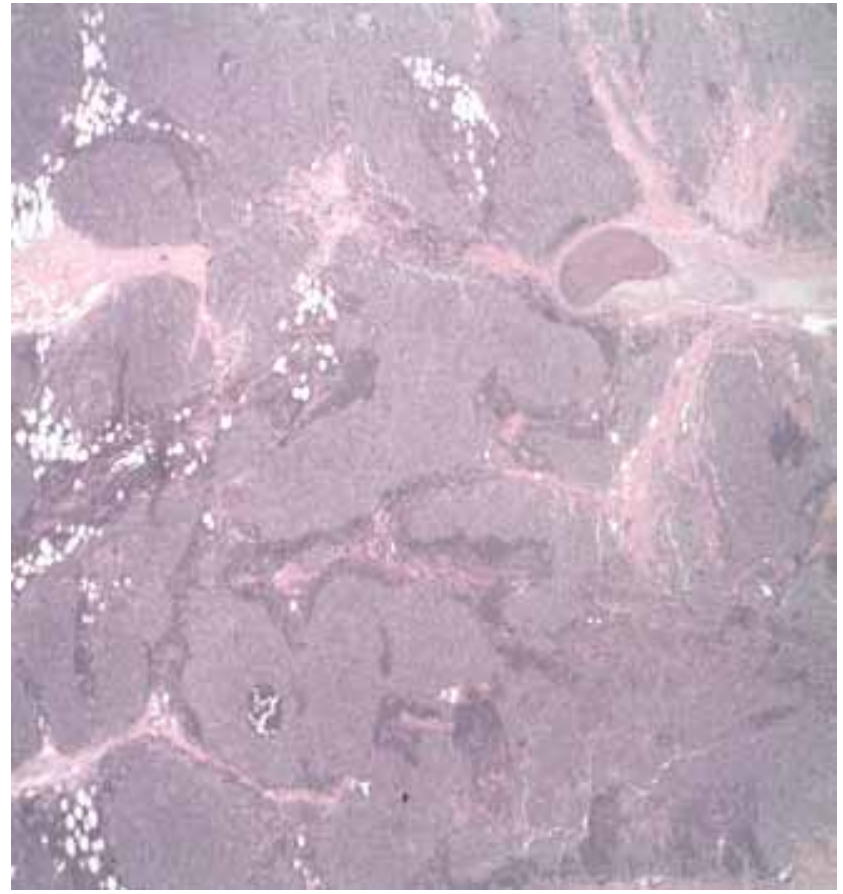

Figure 1. Lymphocytes forming large irregular follicles

Treatment options available are radiotherapy, surgical excision, intralesional interferon alpha and intralesional or systemic rituximab. ${ }^{6}$ Unfortunately, large trials comparing different treatment options are lacking because of rarity of the disease. At present, there is no consensus regarding the initial treatment of choice. In a large multicenter, retrospective study, complete remission was achieved in $100 \%$ of patients with primary cutaneous follicle center lymphoma treated with radiotherapy. 5 Only 8 of 101 patients included in this study had multifocal disease. Twenty nine patients $(28.7 \%)$ relapsed after initial treatment.

Similarly, in another retrospective study, 64 patients with PCFCL were treated with surgical excision. ${ }^{7}$ Complete remission was achieved in 62 patients (96.8\%) among which 23 cases relapsed (37.1\%). All 64 patients had single and small cutaneous lesions. Intralesional IFN alpha for the treatment of PCFCL has been reported in 7 cases. Complete remission rate is $100 \%$, with a relapse rate of $28.57 \% .^{6}$

Reported treatment of 104 cases with multi-agent chemotherapy has shown a complete remission rate of $84 \%$ and a relapse rate of $48 \%$. Most of these patients had disseminated cutaneous lesions. Treatment was mostly comprised of CHOP or CHOP-like courses. ${ }^{6}$ Intralesional use of rituximab has been reported in 12 cases of PCFCL among which 10 cases achieved complete remission $(83.33 \%)$ and the remaining two had partial remission. Four of 10 patients with complete remission (40\%) developed new skin

lesions: two in the originally treated site and two at distant skin sites. ${ }^{6}$

In a report of 11 patients with follicle center lymphoma treated with rituximab, there was $100 \%$ response rate. Complete remission was achieved in 10 patients. Significantly, most of the patients $(64 \%)$ had multifocal disease. ${ }^{8}$

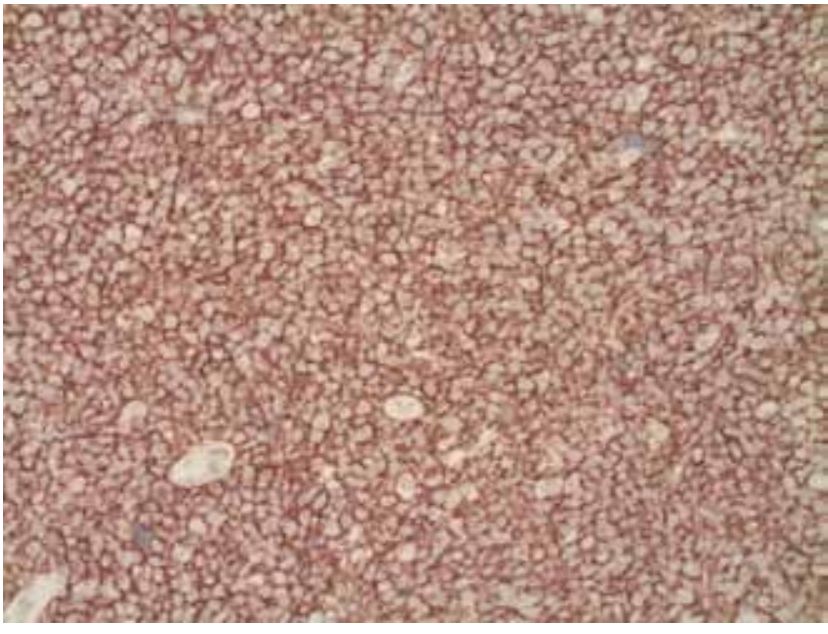

Figure 2. Neoplastic cells expressing CD20

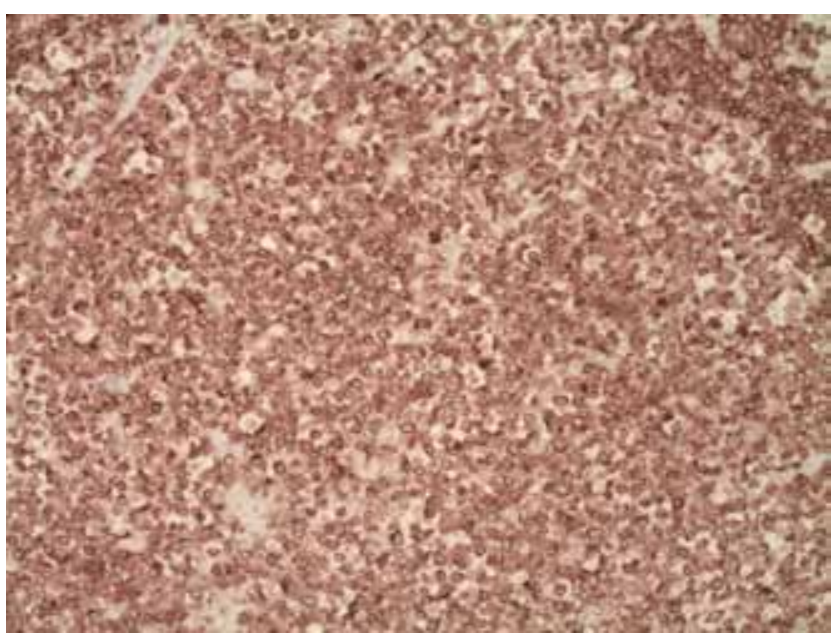

Figure 3. Lymphocytes expressing CD79a

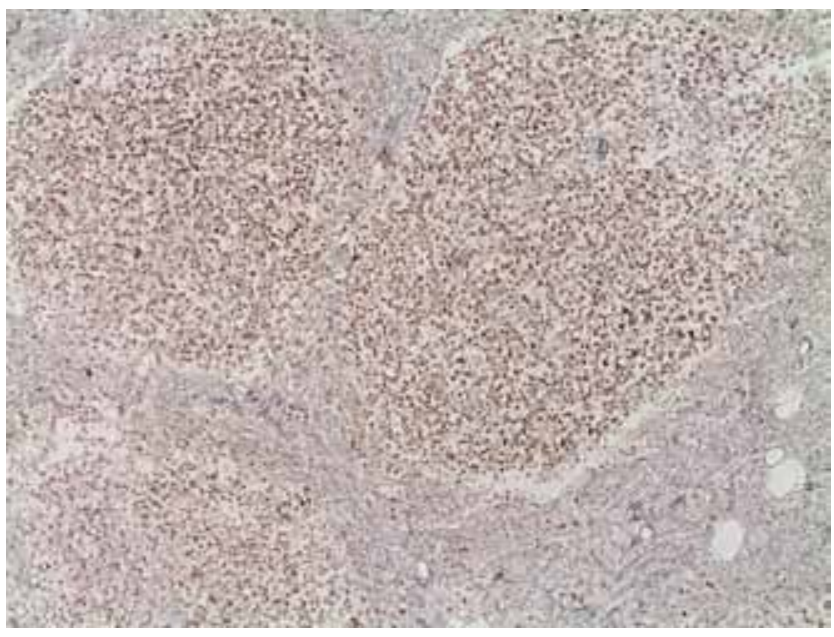

Figure 3. Follicle composed of B celss with strong bcl6 positivity 
Clearly, there are several options for the treatment of cutaneous follicle center lymphoma. The various treatment modalities are effective but had differ in their side effect profile. For example, local treatment modalities like surgery and radiotherapy may cause esthetic impairment. Similarly, systemic treatment with rituximab is associated with few side effects including allergy and infections. Due to absence of randomized clinical trials, there is no clear consensus about the treatment modality of choice in PCFCL. Treatment of this disease should be guided by discussion with the patients about risks and benefits of each approach.

\section{CONCLUSION}

There are several options for treatment of PCFCL. In the absence of data from large clinical trials, treatment of this disease should be individualized.

\section{REFERENCES}

1. Groves FD, Linet MS, Travis LB, et al. Cancer surveillance series: non-Hodgkin's lymphoma incidence by histologic subtype in the United States from 1978 through 1995. J Natl Cancer Inst. 2000;92: 1240-1251.

2. Willemze R, Kerl H, Sterry W, et al. EORTC classification for primary cutaneous lymphomas: a proposal from the cutaneous lymphoma study group of the European Organization for Research and Treatment of Cancer. Blood. 1997;90:354.

3. Swerdlow SH, Campo E, Harris NL, et al. World Health Organization Classification of Tumours of Haematopoietic and Lymphoid Tissues, 4th Edition. IARC Press, Lyon, 2008.

4. Bradford PT, Devesa SS, Anderson WF, et al. Cutaneous lymphoma incidence patterns in the United States: a populationbased study of 3884 cases. Blood. 2009;113:5064-73.

5. Senff NJ, Hoefnagel JJ, Neelis KJ, et al. Results of radiotherapy in 153 primary cutaneous B-Cell lymphomas classified according to the WHO-EORTC classification. Arch Dermatol. 2007;143:1520-6.

6. Senff NJ, Noordijk EM, Kim YH, et al. European Organization for Research and Treatment of Cancer and International Society for Cutaneous Lymphoma consensus recommendations for the management of cutaneous B-cell lymphomas. Blood. 2008;112:1600-9.

7. Zinzani PL, Quaglino P, Pimpinelli N, et al. Prognostic factors in primary cutaneous B-cell lymphoma: the Italian Study Group for Cutaneous Lymphomas. J Clin Oncol. 2006;24:1376-82.

8. Valencak J, Weihsengruber F, Rappersberger K, et al. Rituximab monotherapy for primary cutaneous B-cell lymphoma: response and follow-up in 16 patients. Ann Oncol. 2009;20:326-30. 